\title{
Rational Selection vs. Academic Failure
}

\section{A Response to Van Cleve Morris}

\section{Dear Professor Morris:}

I am frustrated and confused by your article, "Grades for Teachers", 1 in which you argue that to improve the quality of public school teaching we teacher educators must increase the number of teacher candidates, discover those qualities which contribute most directly to good teaching, and become "hard-boiled," honest, and objective in our use of grades for selective purposes. Although I agree with many of your supporting arguments, I find myself in conflict with others; and what is most confusing, I cannot seem to find logical support among your premises for what I believe is your major recommendation for immediate action: the flunking and down-grading of more education students.

First let me say that I, too, would like to help relieve the teacher shortage. It would be a noble thing to do. But I agree that the immediate prospect of doing something significant in this area seems rather discouraging, so I will go on to describe my reactions to your more practical considerations.

I fully agree with your contention that both reliability and validity of our contemporary achievement grades are far too low to warrant their humane or realistic use as the major predictors of students' teaching effectiveness, or, therefore, as sound bases for systematic selection and rejection. In addition, I believe the teacher-student relationship which is established when a student is encouraged to depend completely on his teacher's judgment for his own final assessment of his competences violates an important purpose of any professional education program by thwarting that student's development of mature confidence in his own capacity for self assessment. Do not misunderstand me. I'm not yet in favor of throwing out the grading system. Its diagnostic value (when this is actually applied) is important; and at this time I believe we all derive an important measure of security from its use. But we are in agreement (I believe) that it needs a lot of modification in

\footnotetext{
"Van Cleve Morris, "Grades for Teachers," The Journal of Teacher Education 7: 244-249; September, 1956.
}

the direction of clarifying both the criteria upon which grades are awarded and their predictive validity before it can be confidently used in the separation of potentially competent from potentially incompetent teacher trainees.

This, Professor Morris, is the point $I$ felt you were making in your summary of reasons for the relatively high grades you say we give to education students. But in your next and concluding paragraphs $I$ became confused; I was unable to see any logical process by which you were able to derive the conclusion that teacher educators should eliminate more trainees from this premise that teacher educators do not now know criteria by which success in teaching can be efficiently predicted. Why, I wondered, did you even bother to develop this major premise if you planned to just leave it standing without relating it to your conclusion? And on what premise, then, do you base this recommendation that we flunk and downgrade more students? Simple allegation of an opinion certainly doesn't compel belief.

Another difficulty I experience with your paper is the implicitness of its contention that present rates of trainee rejection are dangerous or harmful. My questions are: Harmful for what? And how? We might agree that we're graduating some incompetent teachers and that this has dangerous consequenes. But we might not agree so easily when we compare the things we believe to be specific teacher incompetences, the ways in which we believe these result in specific dangers to individuals or to society, and how all this relates to sheer rates of rejection based on contemporary grading practices. In fact, I'm not perfectly convinced that there is a very high causal relationship between the simple rate of trainee rejection and the quality of our product. Perhaps we're both encouraging and rejecting too many of the wrong people, in which case alteration of our present criteria might allow us to improve teacher quality while maintaining our present "high" rates of teacher production. Such an hypothesis might enrage those few within and outside of our field who experience an immediate red-flag reaction to the slightest hint of "low academic standards"; but who can definitively deny it at this time? 
And what of those whom we do reject midway through their professional preparation? I agree that when we are convinced an individual will perform in a dangerous or incompetent manner as a teacher it is our first professional responsibility to see that he does not become a teacher. But does our responsibility end here? Are we to assume that if an individual cannot teach, he is a total loss to society? Is it being "soft-hearted" to insist, as I have done elsewhere. ${ }^{2}$ that it is neither humane, realistic, nor in keeping with our professional obligation to society to expect teacher educators to "dump" students from their programs with no accompanying effort to assist them in making new emotional and vocational adjustments?

Finally, I agree with you that the problem of developing valid criteria for professional selection is not ours alone. Faculties in other professions (whether they recognize it or not) face it, too, even though the peculiarly complex socio-emotional nature of our stock-in-trade probably makes it more urgent and difficult in our case. The commonality among all professions is the aim to constructively change the life or living conditions of the client. But while the physician and dentist may attempt this by making direct structural or chemical changes in the client's person, the lawyer alters his social or economic environment, and the architect modifies his physical environment, the teacher has the most complex task of constructively revising or reinforcing his fundamental intellectual or attitudinal relationships to the world. This, as any psychotherapist or insurance salesman would testify, requires more than just knowledge of facts. To the extent that we are able to do it at all, it probably takes friendly, constructive social attitudes, keen sensitivity to others' interest, a feel for the use of motivational principles, group membership and leadership skills, and a variety of other abilities which far transcend the limitations of existing paper-andpencil tests to adequately assess. And these are precisely the kinds of professional characteristics which most clearly differentiate our training requirements-and, therefore, our criteria for selection-from those of other professional groups. A surgeon, for example,

${ }^{2}$ Thomas S. Parsons, “A Student Participation Program for the Training, Counselling, and Selection of Prospective Teachers," World Mental Health 7: 216-236; November, 1955. can afford to be a choleric tartar, for his insults aren't very offensive to the patient under ether and a dentist or architect can easily survive extreme eccentricities if his technical knowledge and manipulative skills regularly produce excellent concrete results. But where social interaction and the communication of ideas are both stock-in-trade and the medium through which the goods are delivered, as is true in professional education, evaluation of these primarily social and emotional characteristics must lie at the very core of any valid assessment of professional competence.

My own conclusion, therefore, is that we should-as you have suggested-look to the future by applying our best research efforts to the validation or rejection of existing criteria for teacher selection and to the discovery and refinement of new valid criteria. But for the immediate task of selecting tomorrow's teachers, I fail to see why we must remain shackled to the rubber yardstick of academic achievement grades, alone. I cannot agree with you that these sheer intellective measures are so notably "solid" as predictors of teaching success. Unless your Rutgers test-makers are a superior breed I doubt that they would bet a month's salary any faster than I would on the accuracy with which their achievement grades are able to predict a student's behavior too far beyond his ability to flail a pen. (And might I suggest that if it is "brains" you want to gaugethe only valid instrument $I$ know is a butcher's scale, although even this might not be very helpful in estimating the owner's ability to solve classroom problems.) It's probably true, in general, that available methods of assessing or predicting characteristics other than pure academic achievement have nothing more to offer in the way of reliability and validity-all of our yardsticks are elastic. But the point is that other methods-such as clinical interviews and inventories, controlled observation of behavior samples, self-and-group-evaluation, etc,-are available. We have already begun to use them with profit in other contexts; and it is not to our advantage if we do not begin to apply them, where appropriate, in this vital area, too. ${ }^{3}$ I feel we do not underrate the value of sheer academic knowledge when we insist that other components of the teacher's role are at least as important. After

${ }^{3}$ Ibid., p. 218-22. 
all, if the teacher's central task is to transmit or facilitate the acquisition of knowledge as well as values, then it is important that he acquire a parcel of facts to transmit and some ideas on how to go about it. But this is no more than a beginning; and $I$ doubt that failure in this area accounts for a disproprotionately high percentage of all onthe-job failures in teaching.

My summary is this: I agree that we do not now have adequate criteria or precise enough evaluative instruments on which to base a rigorous and valid teacher selection program. I also agree that we must-through research-"get straightened out soon on just what qualities make the master teacher" and how to measure them. But I do not see any way in which these considerations justify increasing our reliance upon academic achievement grades as the sole predictors of teaching success. Nor do I see any justification in them for your strong implication that we are likely to significantly increase the general quality of teaching by simply increasing our courses' flunk rates. On the contrary, I feel that they indicate our need to rigorously examine our psychological measurement repertoire for existing devices-in addition to tests of academic achievementwhich may be applied fruitfully to this most pressing problem. I am not at all concerned that some few members of sister professions may point shaming fingers at us for our lesser emphasis on academic standards; their professional functions aren't usually as psychologically intimate as ours almost uniquely are, and they may do better by re-examining their own criteria for professional selection than by expressing their ignorance in a field whose problems obviously confuse them. I am, however, concerned about those few within our own ranks whose shallow convictions and craving for professional "respectability" permit them to be shamed into arbitrarily raising our academic failure rate in these times of critical national teacher shortage.

Thomas S. Parsons School of Education University of Michigan Ann Arbor, Michigan

\author{
Author's Reply \\ Dear Professor Parsons: \\ Your reaction to "Grades for Teachers" is \\ most interesting and provocative, and your
}

remarks are-with the possible exception of the facetious detour into butcher's scalesintelligent, incisive, and to the point. I am troubled somewhat that my essay has led to confusion and frustration-to use a couple of your terms-but, the English language and my prose being what they are, perhaps we cannot avoid these hazards altogether.

Specifically, I want to correct some misinterpretations of my remarks. I do not believe I said that teacher trainers should 'dump' students from their programs with no accompanying effort to assist them in making new emotional and vocational adjustments." I do not believe I said that "we must remain shackled to the rubber yardstick of academic achievement grades, alone," or that these are "notably 'solid' as predictors of teaching success" (author's italics). I do not believe I said or even intimated that we would be justified in "increasing our reliance upon academic achievement grades as the sole predictors of teaching success." I do not believe I recommended the immediate "flunking and down-grading of more education students," nor "arbitrarily raising our academic failure rate in these times of critical national teacher shortage." I charitably submit that, in these and other instances, you are reading between the lines what is not actually there.

What did I say? I think my case might be restated in this way. The "wash-out" rate in teacher education is extremely low. Almost any student who chooses to train for teaching can gain admittance to a teacher training institution, pass the courses, graduate, and be certified to teach. A low "wash-out" rate is not a direct cause of our difficulty. (If I gave this impression in my essay, as you seem to indicate. I apologize for it and wish to correct it here.) $A$ low "wash-out" rate is only a symptom of our trouble. Specifically it is a symptom of one of two things: either (a) we get only able and potentially competent students in our programs (able in terms of personality characteristics, facility in human relations, classroom teaching performance, or whatever teaching training institutions are looking for), or (b) we do not have rigorous criteria and standards of selection. I stand on the conviction that the low "wash-out" rate signifies one or the other of these two conditions. 
Condition (a) does not square with my experience. Condition (b) seems to me to be the culprit.

Condition (b) is intolerable for any profession, but especially for the profession of education which is so strategic an agency in modern civilized societies. Your penetrating and incisive Paragraph 7, beginning "Finally, I agree ....," in which you analyze the function of the educational vis-a-vis the other professions, documents this point far better than I could. ". . . the teacher has the most complex task ..." Yes, indeed, and yet practically anybody can pass some education courses and get a teaching license from the state, certifying that he is competent to perform this "most complex task," i.e., anybody can teach.

Let us correct condition (b). If this be faintness of heart before the onslaughts of our critics, I plead guilty, except to say that it sometimes takes greater fortitude to critizice in one's own house. If this reveals the shallowness of my convictions as to the professional integrity of teacher education programs in the United States, then you have got me about right. And if a "craving for professional respectability" is a new crime in our order, let me be first in line to take the cup of hemlock.

Respectability, with or without quotation marks, is partly what others think of us; but also what we think of ourselves. Our fellows in the other professions have withheld their approval not because we have abandoned the narrow intellectual and academic standards but because we have apparently abandoned all standards and let everybody through. We ourselves, in the name of self-respect, ought to do something about this. I write pieces like this ${ }^{4}$ not to carp and destroy, but to summon my colleagues to a program of reform in teacher education which I consider long overdue.

Van Cleve Morris Rutgers University

${ }^{4}$ See also V. C. Morris, "A Lover's Quarrel with (Capital 'E') Education," Educational Forum, (a forthcoming issue).

Teaching was the chosen career of 30 per cent of the nation's top high school students replying to a questionnaire last year, the National Association of Secondary-School Principals reports. Next highest choice was engineering, with 16.7 per cent. Others ranged from 10.7 per cent downward. The report was based on replies from the 12,154 student members of the National Honor Society who were eligible to enter the annual scholarship competition. These were collegebound seniors who stood in the top five per cent of their classes.

Of the 30 per cent selecting teaching as a career, only 455 were boys while 3,199 were girls. Of the total number competing, 5,280 were boys and 6,874 were girls.

Other career choices were: science research, 10.7 per cent; medicine, 9.4 per cent; business, 7 per cent; nursing, 3.9 per cent; communications, 2.5 per cent; law, 2.2 per cent; government, 2.1 per cent; creative arts, 2 per cent; ministry, 1.8 per cent; home economics, 1.6 per cent; social work, 1.5 per cent; agriculture, .8 per cent; dentistry, .5 per cent; miscellaneous, 1 per cent; and undecided, 6.4 per cent. 